\title{
Research on the Construction Method of Intelligent Prediction and Analysis Model for the Whole Process of Power Grid Project Cost
}

\author{
Zuobin Liang ${ }^{1, *}$, Shan $\mathrm{Gao}^{1}$, Qing Wang ${ }^{1}$, Yong Dai ${ }^{1}$, Peng Rong ${ }^{1}$, Jun $\mathrm{Ye}^{1}$, Yunxing Gao ${ }^{1}$ \\ ${ }^{1}$ State Grid Shandong Electric Power Company Taian Power Supply Company, Shandong Province, Taian; 271000, China
}

\begin{abstract}
The government's supervision of power grid enterprises will gradually focus on the transmission and distribution price, and the investment and income will be more strictly supervised. Under the new management requirements, the company must pay more attention to the compliance of the investment process, further strengthen the investment risk control, put an end to inefficient or invalid investment, strengthen the all-round and whole process supervision, and scientifically and accurately determine and carry out effective project cost control and management. It is the key to achieve project management objectives, and also an important measure of investment fine management and control. This paper takes historical cost data as the research object, constructs the whole process intelligent prediction and analysis model of power grid project cost, assists investment decision-making, reduces the balance rate, and improves the efficiency and efficiency of the company's investment and lean management level.
\end{abstract}

\section{Research background}

In recent years, the investment projects of power transmission and transformation projects are increasing year by year, and the scale of power construction is also expanding. There is a certain difference between the project investment estimation and the actual project cost, which is not conducive to the accurate cost control, resulting in a relatively high cost balance rate. The power grid cost is an important support and analysis basis for enterprise investment planning, and an important tool for enterprises to strengthen investment control. The government's supervision of power grid enterprises will gradually focus on transmission and distribution electricity prices, and investment and income will be subject to more strict supervision. Under the new management requirements, the company should pay more attention to the compliance of investment process, further strengthen investment risk management and control, and put an end to low efficiency or low efficiency Invalid investment, strengthening all-round and whole process supervision, scientifically and accurately determining and carrying out effective project cost control and management are the key to achieve the project management objectives, and are also important measures for investment fine control. Therefore, it is necessary to study historical project cost information, fully excavate and make full use of historical cost data to support the calculation of investment in the planning stage and the review of investment estimates in the feasibility study stage, Investment control target forecast in the planning stage, and improve the company's lean investment management level.

\section{Construction framework of intelligent prediction and analysis model for the whole process of power grid project cost}

Based on completed final accounts of power grid infrastructure projects of $35 \mathrm{kV}$ and above, and individual real-time cost data, build a real-time basic cost database, use statistical analysis methods and artificial intelligence algorithms to build cost prediction models, and use combination weighting on the prediction results to achieve project cost Prediction. At the same time, the intelligent analysis and evaluation model of cost is constructed to realize the intelligent analysis and evaluation of project cost. The specific model construction framework is shown in the figure below:

\footnotetext{
* Corresponding author: 14259069@qq.com
} 


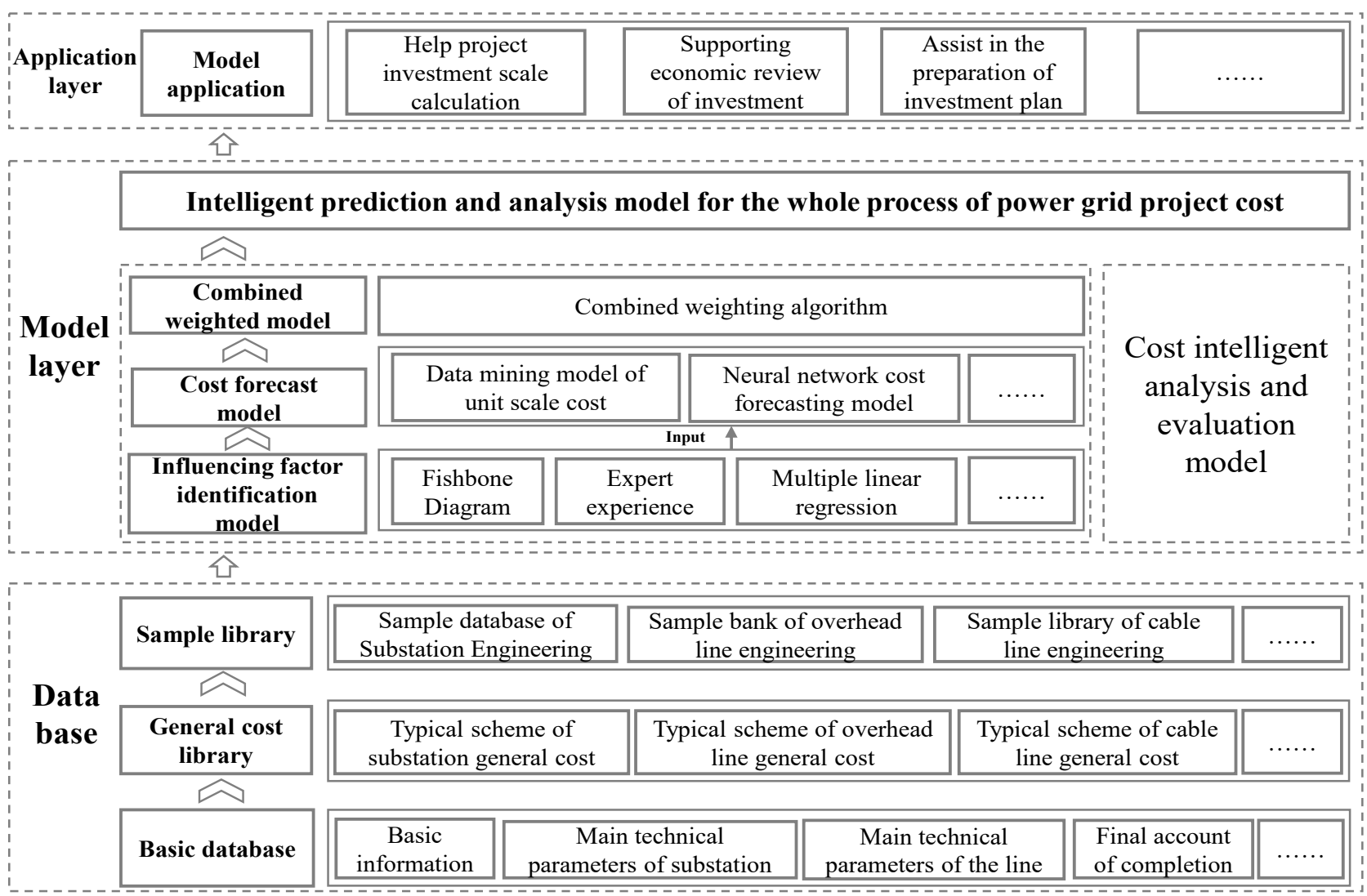

Figure1. Construction framework of intelligent prediction and analysis model for the whole process of power grid project cost

\section{Intelligent prediction model for the whole process of power grid cost}

\subsection{Construction of real-time cost basic database}

\subsubsection{Design data templates and collect data}

The template of power grid infrastructure project cost basic database is designed, the required fields of power grid engineering cost basic database are defined, and the real-time cost data of completed final accounts of power grid infrastructure projects of $35 \mathrm{kV}$ and above and single real-time cost data are collected, covering three categories of basic information, technical conditions and value information of power grid project in the whole process, so as to build a real-time cost basic database.

\subsubsection{Design data verification logic}

Design the verification logic of the integrity and accuracy of the basic cost database data, realize the automatic inspection and verification of the rationality of the basic data based on the basic business laws, and ensure the quality of the basic data. For the suspected problem samples that are not included in the model calculation, the specific verification logic is as follows:

- Check whether the key value information is empty.

- Judge whether the logic of budget estimate and final account data is reasonable. Check formula:
$\Sigma$ four items of budgetary estimate cost $=$ dynamic investment of budgetary estimate

$\Sigma$ four items of cost of final account=dynamic investment of final account

If the total of the four expenses is not equal to the dynamic investment, the logic is unreasonable and it is judged as a suspected problem sample.

- Judge whether the difference between the four cost structure of the budget estimate and the company's average structure level is reasonable. Calculate the proportion of the four costs of the estimated budget to the estimated dynamic investment, calculate the deviation of the four cost structure of the budget estimate from the average structure of the company, and if the difference of a certain cost exceeds $10 \%$, it is judged as a suspected problem sample.

- Judge whether the deviation of the four cost structures between the budget estimates and the final accounts is reasonable. The difference between the four items of the estimated costs in the estimated dynamic investment and the four items of the final budget in the final dynamic investment. If the difference in a certain item exceeds $20 \%$, it is judged as a suspected problem sample.

-Determine whether the dynamic investment balance rate of a single project exceeds $30 \%$. Determine whether the balance rate of a single project dynamic investment exceeds $30 \%$ (tentatively $30 \%$, and can be adjusted manually according to the sample situation of the suspected problem). If the absolute value of the single project dynamic investment balance rate exceeds $30 \%$, it is judged as a suspected problem sample. 


\subsection{Classification to form a sample library}

Considering the operability of the application, three technical conditions, voltage level, substation type and distribution device type, are considered in the planning and feasibility study stage of the substation project. The $110 \sim 750 \mathrm{kV}$ power grid infrastructure project is divided into 16 categories in the planning stage and 30 categories in the feasibility study stage.

Overhead line project in the planning stage, considering voltage grade back, wire model three technical conditions, in the feasibility study phase, considering voltage grade back, wire type five technical conditions, ice, wind speed, and refer to the general design scheme (each project involves multiple general overhead line engineering design, generally choose the most main general design), $110 \sim 500 \mathrm{kV}$ power grid infrastructure projects in the planning stage is divided into class 43 , in the feasibility study phase is divided into 70 classes.

\subsection{Automatic identification algorithm of influencing factors}

According to the classification of engineering types, intelligent cost prediction models identify the main influencing factors of substation engineering and line engineering cost respectively, and adopt expert experience, factor analysis method, multiple linear regression and other factor identification methods to identify the main influencing factors of engineering cost, and finally determine the input parameters of the model. The specific steps are shown in the figure below:

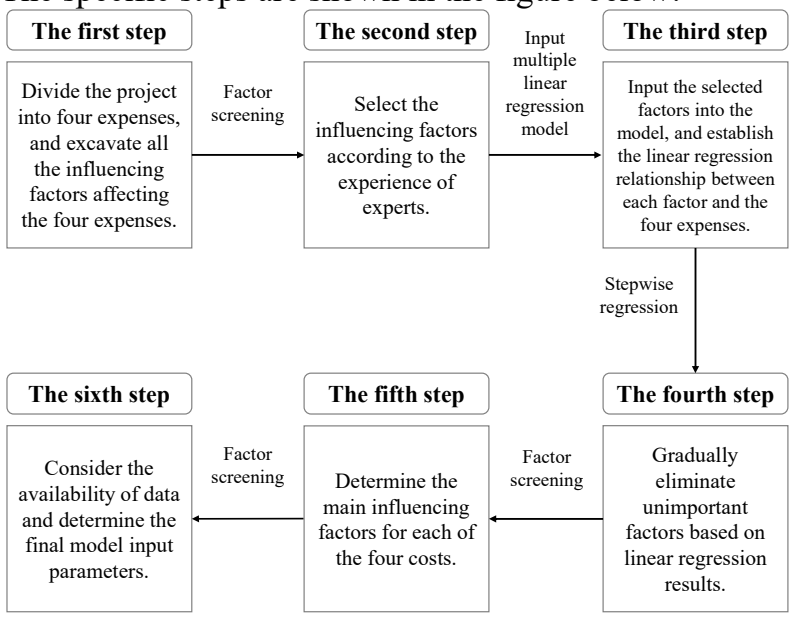

Figure 2. Automatic identification algorithm of influencing factors

\subsection{Build an intelligent predictive model of cost}

In view of the limited historical cost data, artificial intelligence algorithm training needs a large number of samples to improve the accuracy of the model. Therefore, based on the current data collection background, the descriptive statistical method and artificial intelligence algorithm are used to predict the project cost. Finally, the weight is given according to the deviation of the prediction results, and the applicability of the model is improved.

\subsubsection{Data mining model of unit scale cost}

Based on the general design or general cost typical scheme library, this paper uses statistical analysis method to calculate the average cost, cost interval and unit scale cost level of various types of projects, and establishes the standard base of unit cost investment reference value.

\subsubsection{Artificial intelligence engineering cost prediction model}

Combined with the objective judgment of mathematical model and subjective prediction of expert experience, the use of neural network intelligent prediction algorithm to establish a prediction model that not only conforms to professional experience but also conforms to mathematical logic, which can improve the accuracy of model selection input variables and model prediction accuracy to a certain extent. For the construction cost, installation cost and equipment purchase cost, the neural network algorithm is used to predict respectively. For other costs, due to the existence of construction site acquisition and cleaning costs and other irregular costs, it does not participate in the neural network prediction. This part of the cost will be summarized into the final prediction value of the model through manual filling. The construction idea of artificial intelligence project cost prediction model based on neural network is shown in the following figure:

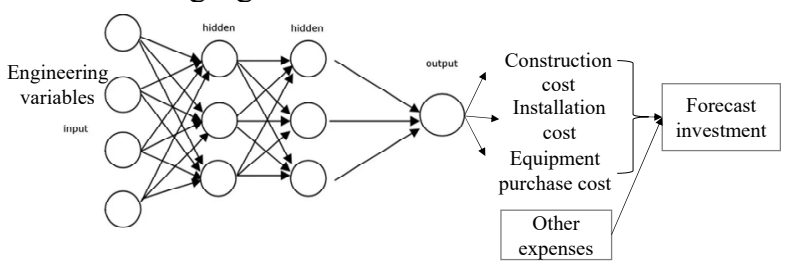

Figure 3. Construction idea of artificial intelligence project cost prediction model based on Neural Network

\subsubsection{Combined weighted model}

Combined with the prediction results of cost prediction models such as unit-scale cost data mining model and neural network, combined weighting algorithm is introduced to realize the combined weighting of the prediction results of multiple models, so as to further improve the applicability and consideration of the cost prediction model. The inverse squares of the error between the predicted values and the actual values of the training sets were taken as weights, and the predicted values and prediction intervals of each model were combined weighted according to the calculated weights. The weight calculation example is as follows:

(1) Taking a certain set of samples as an example, the average error between the predicted value and the actual value of various models is shown as follows: 
Table 1. Examples of average error between predicted and actual values of various models.

\begin{tabular}{|l|l|l|l|}
\hline \multicolumn{1}{|c|}{ Model type } & $\begin{array}{c}\text { Actual value } \\
\text { of static } \\
\text { investment }\end{array}$ & $\begin{array}{c}\text { Static } \\
\text { investment } \\
\text { forecast }\end{array}$ & $\begin{array}{c}\text { Average } \\
\text { error }\end{array}$ \\
\hline $\begin{array}{l}\text { Data mining } \\
\text { model of } \\
\text { unit scale } \\
\text { cost }\end{array}$ & $\mathrm{A}_{\mathrm{i}}$ & $\mathrm{A} 1_{\mathrm{i}}$ & $\mathrm{A} 1_{\mathrm{i}}-\mathrm{A}_{\mathrm{i}}$ \\
\hline $\begin{array}{l}\text { Neural } \\
\text { network } \\
\text { prediction } \\
\text { model }\end{array}$ & $\mathrm{B}_{\mathrm{i}}$ & $\mathrm{B} 1_{\mathrm{i}}$ & $\mathrm{B} 1_{\mathrm{i}}-\mathrm{B}_{\mathrm{i}}$ \\
\hline $\begin{array}{l}\text { Support } \\
\text { vector } \\
\text { machine } \\
\text { prediction } \\
\text { model }\end{array}$ & $\mathrm{C}_{\mathrm{i}}$ & $\ldots \ldots$ & $\ldots$ \\
\hline $\begin{array}{l}\text { no... } \\
\text { (2) }\end{array}$ & $\ldots \ldots$ & $\mathrm{C} 1_{\mathrm{i}}$ & $\mathrm{C}_{\mathrm{i}}-\mathrm{C}_{\mathrm{i}}$ \\
\hline
\end{tabular}

weighted weight of various model results is as follows:

Table 2. Examples of calculation methods for weighted weights of combination of various model results.

\begin{tabular}{|c|c|c|c|}
\hline Model & $\begin{array}{l}\text { Sum of } \\
\text { squares } \\
\text { of } \\
\text { errors }\end{array}$ & $\begin{array}{l}\text { Reciproc } \\
\text { al of sum } \\
\text { of } \\
\text { squares } \\
\text { of errors }\end{array}$ & $\begin{array}{l}\text { The weight } \\
\text { (Normalization } \\
\text { of the reciprocal } \\
\text { sum of squared } \\
\text { errors) }\end{array}$ \\
\hline $\begin{array}{l}\text { Data } \\
\text { mining } \\
\text { model of } \\
\text { unit scale } \\
\text { cost }\end{array}$ & $\begin{array}{l}\left(\mathrm{A} 1_{\mathrm{i}^{-}}\right. \\
\left.\mathrm{A}_{\mathrm{i}}\right)^{\wedge} 2\end{array}$ & $\begin{array}{l}\mathrm{D} 1=1 /(\mathrm{A} \\
\left.1_{\mathrm{i}}-\mathrm{A}_{\mathrm{i}}\right)^{\wedge} 2\end{array}$ & $\mathrm{D} 1 /(\mathrm{D} 1+\mathrm{D} 2+\mathrm{D} 3)$ \\
\hline $\begin{array}{l}\text { Neural } \\
\text { network } \\
\text { prediction } \\
\text { model }\end{array}$ & $\begin{array}{l}\left(\mathrm{B} 1_{\mathrm{i}^{-}}\right. \\
\left.\mathrm{B}_{\mathrm{i}}\right)^{\wedge} 2\end{array}$ & $\begin{array}{l}\mathrm{D} 2=1 /(\mathrm{B} 1 \\
\left.\mathrm{i}-\mathrm{B}_{\mathrm{i}}\right)^{\wedge} 2\end{array}$ & $\mathrm{D} 2 /(\mathrm{D} 1+\mathrm{D} 2+\mathrm{D} 3)$ \\
\hline $\begin{array}{l}\text { Support } \\
\text { vector } \\
\text { machine } \\
\text { prediction } \\
\text { model }\end{array}$ & $\begin{array}{l}\left(\mathrm{Cl}_{\mathrm{i}^{-}}\right. \\
\left.\mathrm{C}_{\mathrm{i}}\right)^{\wedge} 2\end{array}$ & $\begin{array}{l}\mathrm{D} 3=1 /(\mathrm{C} 1 \\
\left.\mathrm{i}^{-} \mathrm{C}_{\mathrm{i}}\right)^{\wedge} 2\end{array}$ & $\mathrm{D} 3 /(\mathrm{D} 1+\mathrm{D} 2+\mathrm{D} 3)$ \\
\hline ...... & ...... & ...... & ...... \\
\hline
\end{tabular}

\subsubsection{Investment reference value and reference interval considering balance ratio}

Since the combined forecast result is a forecast value based on the final accounting data, to meet the application requirements at different stages, it is necessary to calculate the balance ratio between the cost and the final accounting data at different application stages to obtain the investment reference value and reference interval for different application stages.

(1) Calculate the balance rate

Feasibility study stage balance rate $=$ (estimated static investment-final static investment) / estimated static investment.

(2) Investment reference value and reference interval considering balance rate

Investment reference value $=$ portfolio weighted investment reference value $*(1+$ balance rate $)$.

Upper limit of investment reference value interval $=$ upper limit of investment reference value interval weighted by portfolio * $(1+$ balance rate $)$.

Lower limit of investment reference value interval $=$ lower limit of investment reference value interval weighted by portfolio $*(1+$ balance rate $)$.

\section{Intelligent cost analysis evaluation model}

\subsection{Intelligent cost analysis model}

Make full use of historical cost database, through big data mining and other means, extract appropriate cost analysis data for calculation and training, and construct cost intelligent analysis model to optimize engineering investment parameters of various business departments and meet the application requirements of different business departments. The specific contents of intelligent analysis are as follows:

\subsubsection{Calculation and warning of investment balance rate}

Extract the relevant fields needed to calculate the balance rate from the real-time cost database, including basic information (voltage level, construction nature, single project type), value information (feasibility study estimate, preliminary estimate, final account after completion), and calculate the balance rate of each individual item, Set the balance rate parameter according to the calculation result, calculate the balance rate level of the project to be measured, compare it with the balance rate parameter level, and provide early warning tips for items with excessive balance rate.

\subsubsection{Cost analysis}

Select the project with high balance rate for key analysis, including the overall balance rate analysis, sub item cost balance rate analysis, key project balance rate analysis, and find out the key control factors affecting the investment, calculate the reasonable range of main 
equipment and engineering quantity, and form the key investment control measures.

\subsection{Post investment evaluation model}

Effectively correlate the "five calculations" data, automatically measure the deviations between the estimates and estimates, settlement and estimates, final accounts and settlements, capital transfer and final accounts, automatically calculate the investment balance rate and capital transfer rate at each stage of the project, and build a post-investment evaluation model, For data with large deviations, it can automatically compare and form the reasons for deviations, such as: design depth differences, material and equipment price changes and other factors, and find out the internal factors that affect the project investment balance rate and capital conversion rate.

\section{Conclusion}

Based on the historical cost data of $35 \mathrm{kV}$ and above power grid infrastructure projects, this paper constructs a real-time cost basic database, fully excavates the historical cost information of the database, and constructs an intelligent analysis model for the whole process of power grid cost by using various calculation methods such as descriptive statistics and artificial intelligence. The model can predict the cost of different stages of investment, analyze the causes of cost deviation, and post investment evaluation multiple functions to assist the accurate decision-making of power grid infrastructure investment and improve the investment efficiency and efficiency of power grid enterprises.

\section{References}

1. Wang, W.L., (2017) Research on Cost Management of the Whole Process of Power Grid Engineering Construction. North China Electric Power University.

2. Yu, C., (2016) Study on the Influencing Factors and Evaluation Model of Power Grid Project Cost. North China Electric Power University.

3. Liu, X., (2017) Research on Cost Control Evaluation of Power Grid Project of Tianjin Electric Power Company. Tianjin University.

4. Lu, Y., (2016) Research on Dynamic Management Model of Power Grid Project Cost Based on Target Control. North China Electric Power University.

5. Wu, D., (2019) Research on Application of Theory and Method Model of Transmission and Distribution Project Cost Analysis. Experience Exchange.

6. Wu, M, Q., (2018) Study on Influencing Factors and Prediction Model of Equipment and Material Price in Power Grid Engineering. North China Electric Power University.
7. Zhao, Y, Q., (2018) Research on the Establishment and Application of Overhead Line Engineering Cost Interval and Engineering Quantity Interval. North China Electric Power University. 